\title{
Overutilization of surgical resection for benign colorectal polyps: analysis from a tertiary care center
}

\section{(ㄷ)(1)}

Authors

Rayan Saade ${ }^{1}$, Tyler Tsang ${ }^{2}$, Michel Kmeid ${ }^{1}$, David Miller ${ }^{2}$, Zhiyan Fu', James Litynski ${ }^{3}$, Patrick Young ${ }^{4}$, Joseph C. Anderson ${ }^{5,6}$, Hwajeong Lee ${ }^{1}$, Micheal Tadros ${ }^{3}$

Institutions

1 Pathology and Laboratory Medicine, Albany Medical Center, Albany, New York, United States

2 Albany Medical College, Albany, New York, United States

3 Gastroenterology, Albany Medical Center, Albany, New York, United States

4 Gastroenterology Service, Department of Internal Medicine, Walter Reed National Military Medical Center, Bethesda, Maryland, United States

5 Department of Veterans Affairs Medical Center, White River Junction, Vermont, United States, and The Geisel School of Medicine at Dartmouth, Hanover, New Hampshire, United States

6 Division of Gastroenterology and Hepatology University of Connecticut School of Medicine, Farmington, Connecticut, United States

submitted 2.8.2020

accepted after revision $\quad 28.12 .2020$

\section{Bibliography}

Endosc Int Open 2021; 09: E706-E712

DOI 10.1055/a-1380-3017

ISSN 2364-3722

(c) 2021. The Author(s).

This is an open access article published by Thieme under the terms of the Creative Commons Attribution-NonDerivative-NonCommercial License, permitting copying and reproduction so long as the original work is given appropriate credit. Contents may not be used for commercial purposes, or adapted, remixed, transformed or built upon. (https://creativecommons.org/licenses/by-nc-nd/4.0/)

Georg Thieme Verlag KG, Rüdigerstraße 14,

70469 Stuttgart, Germany

\section{Corresponding author}

Micheal Tadros, MD, Albany Med Gastroenterology, 1769 Union Street, 2nd Floor, Schenectady, NY 12309, United States

Fax: +1-518-881-0003

Tadrosm1@amc.edu
Supplementary material is available under https://doi.org/10.1055/a-1380-3017

\section{ABSTRACT}

Background and study aims Adequate removal of precancerous polyps is an independent factor in colorectal cancer prevention. Despite advances in polypectomy techniques, there is an increasing rate of surgery for benign polyps. We assessed whether surgical resection is properly utilized for benign colorectal polyps.

Patients and methods We identified 144 patients with surgical resection for benign colorectal polyps. Polyp location, size and the indication for and type of surgery were obtained. For the purposes of this analysis, we assumed that gastroenterologists should assess polyp size accurately, endoscopically resect polyps $<2 \mathrm{~cm}$, and treat incompletely excised polyps on follow-up.

Results A total of 118 patients ( $82 \%$ ) were referred to surgery without attempted endoscopic removal. In 26 (22\%) of 118 , the macroscopic polyp size was $<2 \mathrm{~cm}$ (23 in right, 3 in the left colon) and 18 (15\%; 14 in the right, four in the left colon) were found to have had size overestimation during endoscopy. Twenty-two (15\%) of 144 underwent surgical resection for incomplete endoscopic resection of adenomas (16 in the right, 6 in the left colon); 12 (54.5\%) had a residual polyp size of $<2 \mathrm{~cm}$ (10 in the right colon; 2 in the left colon). In-hospital mortality was $0.7 \%$ and morbidity was $20.1 \%$.

Conclusions of the patients, $41 \%$ could have potentially avoided surgical intervention (37 polyps $<2 \mathrm{~cm}$ and/or size overestimations precluding endoscopic polypectomy and 22 incomplete resections). When including polyps with size $\geq 2$ to $<4 \mathrm{~cm}$, the percentage of patients with avoidable surgery reached $80 \%$. This confirms the need to develop standardized quality metrics for endoscopic polypectomies and for better overall training of endoscopists performing these procedures. Given the risks of surgery, referral to an experienced gastroenterologist should be considered as a first step. 


\section{Introduction}

Large and complex colorectal polyps were traditionally managed using surgical resection. The shift to endoscopic management was primarily due to improvements in procedural risks, safety and cost-effectiveness of endoscopic polypectomy over surgical resection [1-4]. More importantly, endoscopic resection showed comparable efficacy to surgery in preventing colorectal cancer [5]. Specialized approaches to endoscopic resection, such as endoscopic mucosal resection (EMR) and endoscopic submucosal dissection (ESD), initially used in the treatment of gastric cancer, have made it possible to safely resect large $(>2 \mathrm{~cm})$ sessile and flat neoplastic colonic polyps as well as superficially invasive malignant polyps in some instances. According to the US Multi-Society Task Force's (USMSTF) most recent guidelines on endoscopic removal of colorectal lesions, nonpedunculated lesions that are 10 to $19 \mathrm{~mm}$ in size can be resected with hot or cold snare polypectomy with consideration for EMR in cases of nonpolypoid or serrated morphology, while nonpedunculated lesions $\geq 20 \mathrm{~mm}$ should preferably be managed by EMR with a provision that these procedures be performed by endoscopists experienced in advanced polypectomy [6]. Despite the apparent efficacy and wide availability of endoscopic polypectomy, the rate of surgical resection for non-malignant colorectal polyps has increased from 5.9/100,000 in 2004 to $9.4 / 100,000$ in 2014 [7]. Over the same time period, the morbidity and mortality rates were $25 \%$ and $0.8 \%$, respectively, in a nationwide sample consisting of over 260,000 surgeries for surgical resections of benign colorectal polyps [8].

Factors responsible for this unexpected trend are not well studied. Potential contributors include the expansion in colorectal screening programs leading to improved polyp detection, the lack of well-defined indications for surgical referral, and the underutilization of advanced endoscopists who are better suited to remove complex polyps. Moreover, factors related to the polypectomy procedure itself should also be evaluated.

The technical aspects of endoscopic polypectomy have been well described. Critical factors include high quality polyp assessment (Paris classification, NICE or KUDO classification, and size estimate,) recognition of features suggestive of submucosally invasive cancer (SMIC), and completeness of resection/recurrence rate. These criteria in conjunction with accessibility (i.e. difficult endoscopic positioning) and morphologic features such as flat and complex polyps with their associated complication risks may lead to variability in defining a "surgical polyp" among different endoscopists [9].

Recently published data show nonadherence to specific polypectomy guidelines by gastroenterologists, sometimes even using inadequate polypectomy techniques [10]. Moreover, incomplete resections of neoplastic polyps are not uncommon, which is concerning, given that incomplete polypectomy has been shown to account for up to $20 \%$ of colorectal cancers detected after the colonoscopy $[11,12]$. While quality metrics regarding polyp detection (adenoma detection rate, ADR) have been formalized, no widely applied measures exist for polypectomy competency. It has also been demonstrated that informal quality measures of adequate polypectomy are an independent factor in colorectal cancer prevention and do not correlate with adenoma detection rates (ADR) [13].

Our study aim is to analyze the different patterns and indications of surgery for non-malignant polyps with failed endoscopic resection and assess the appropriateness of these surgical referrals. We judged the appropriateness of surgical referral based on the most recent USMSTF guidelines on endoscopic removal of colorectal lesions [6]. The primary objective of the study is to determine the percentage of patients with non-malignant colorectal polyps who could have avoided surgical resection and explore the reasons behind it. We also sought to define the characteristics of polyps with failed endoscopic polypectomy which might serve as guidance for focused endoscopist training and developing standardized quality metrics for endoscopic polypectomy.

\section{Patients and methods}

The study was approved by the Institutional Review Board with a waiver of consent. Archived pathology materials from consecutive surgical resections of benign colorectal polyps (20032018) in our tertiary referral center were retrieved and reviewed. Clinicopathologic characteristics including age, gender, polyp location, endoscopic and macroscopic polyp size, type and indication of surgery were obtained from electronic medical records (EMR). Two pathologists, including a gastrointestinal pathologist evaluated archived pathology slides from these resections for polyp type and presence of high-grade dysplasia (HGD). Exclusion criteria included patients undergoing surgery for inflammatory bowel disease and emergency surgeries. We excluded polyps with reported invasive adenocarcinoma on preoperative biopsy. A total of 154 cases of surgically removed benign colorectal polyps from 2003 to 2018 were identified and retrieved. Of 154, 10 cases had reported invasive adenocarcinoma on preoperative biopsy and were excluded from the study. All the remaining cases satisfied our inclusion criteria ( Fig. 1).

Patients included both those initially seen at our institution as well as outside referrals. Indications for surgery were retrieved from surgeons' notes and/or operative reports. A gastroenterologist and two pathologists carefully reviewed these indications. The gastroenterologist was blinded to the referring gastroenterologist. Both pathology residents who retrieved medical records data and reviewed the indications had no knowledge of the referring gastroenterologists. A clear definition of appropriate polypectomy was developed, reviewed with and confirmed by two outside gastroenterologists. For the purposes of our evaluation, we assumed that a general gastroenterologist should be able to assess polyp size accurately, endoscopically resect polyps $<2 \mathrm{~cm}$, and only attempt to remove polyps they can fully excise or follow-up and treat appropriately.

Surgical referrals were subcategorized into appropriate (colorectal polyp size $\geq 2 \mathrm{~cm}$, multiple polyps) and inappropriate. The latter category included polyp size $<2 \mathrm{~cm}$, size overestimation precluding endoscopic polypectomy, or incomplete resection. Size overestimation was defined as a reported endo- 
Patients with surgically removed benign colorectal polyps (2003-2018) $(n=154)$

\begin{tabular}{|c|c|c|}
\hline & \multicolumn{2}{|c|}{$\begin{array}{l}10 \text { patients excluded with adeno- } \\
\text { carcinoma diagnosis on previous } \\
\text { "preoperative biopsy" }\end{array}$} \\
\hline \multicolumn{3}{|c|}{$\begin{array}{l}\text { Patients included with surgically removed benign } \\
\text { colorectal polyps }(n=144)\end{array}$} \\
\hline $\begin{array}{l}\text { Patients } \\
\text { without } \\
\text { attempted } \\
\text { endoscopic } \\
\text { polypectomy } \\
(n=118)\end{array}$ & $\begin{array}{l}\text { Patients with } \\
\text { incomplete } \\
\text { endoscopic } \\
\text { resection } \\
(n=22)\end{array}$ & $\begin{array}{l}\text { Patients with } \\
\text { serrated } \\
\text { polyposis } \\
\text { syndrome or } \\
\text { multiple } \\
\text { polyposis } \\
\text { syndrome } \\
(n=4)\end{array}$ \\
\hline
\end{tabular}

- Fig. 1 Patient identification flow chart

scopic size that was at least one- third or $1 \mathrm{~cm}$ greater than the macroscopic size on final resection.

We analyzed the cohort based on polyp size $<2 \mathrm{~cm}$ versus $\geq 2 \mathrm{~cm}$ and compared characteristics of these two groups. We also compared polyps based on their location. Right or left colon polyps include those either proximal or distal to the splenic flexure, respectively. Polyps were also assessed based on histology (adenoma vs serrated lesion). Statistical analysis was done using chi-square test. All original slides of resected polyps were reviewed by two pathologists, including a gastrointestinal pathologist. The polyps were classified as tubular adenoma (TA), tubulovillous adenoma (TVA), sessile serrated lesion (SSL) or traditional serrated adenoma (TSA). The presence of highgrade dysplasia was also assessed.

The primary objective of the study is to determine the percentage of patients with non-malignant colorectal polyps who could have avoided surgical resection and explore the reasons behind it. We also sought to define the characteristics of polyps with failed endoscopic polypectomy which might serve as guidance for focused endoscopist training and developing standardized quality metrics for endoscopic polypectomy.

\section{Results}

Between January 1, 2003 and December 31, 2018, a total of 57,441 colonoscopies were performed in our institution and affiliated hospitals and ambulatory centers. Our annual number of colonoscopies consistently ranges between 3,000 and 4,000 . A total of 144 cases of surgically removed benign colorectal polyps during that same time period were identified and retrieved. Surgical procedures included right hemicolectomy $(n=101)$, partial cecectomy $(n=1)$, left hemicolectomy $(n=$

\begin{tabular}{|c|c|}
\hline & $N=144$ \\
\hline Age (years), mean (range) & $65(34-94)$ \\
\hline \multicolumn{2}{|l|}{ Gender, n (\%) } \\
\hline - Male & $77(53.5 \%)$ \\
\hline - Female & $67(46.5 \%)$ \\
\hline Diabetes mellitus, n (\%) & $29(20 \%)$ \\
\hline Hyperlipidemia, n (\%) & $69(48 \%)$ \\
\hline Hypertension, n (\%) & $74(51 \%)$ \\
\hline Smoking, n (\%) & $70(49 \%)$ \\
\hline Body mass index $\left(\mathrm{kg} / \mathrm{m}^{2}\right)$, median (range) & $26.9(16.4-46.9)$ \\
\hline
\end{tabular}

10 ), colonic segmental resection ( $n=21$, out of which 10 were sigmoid colectomies), low anterior resection $(n=6)$ and transanal mucosal excision $(n=5)$. Polyp size ranged from $0.5 \mathrm{~cm}$ up to $11.0 \mathrm{~cm}$. The mean patient age was 65 (range $=34-94$ ) years with slight male predilection (male:female =77:67) ( $\triangleright$ Table 1 ). One hundred eighteen patients were referred to surgery without attempted endoscopic removal, 22 patients had recurrence or incomplete polypectomy, and 4 patients had $>10$ adenomas or met criteria for serrated polyposis syndrome ( $\triangleright$ Fig. $\mathbf{1}$ ).

\section{Patients with benign polyps referred to surgery without attempted endoscopic polypectomy}

In $26(22 \%, 95 \% \mathrm{Cl}$ [15.5-30.3]) of 118 polyps, the macroscopic polyp size was $<2 \mathrm{~cm}$, and 56 (48\%, $95 \% \mathrm{Cl}$ [38.7$56.4]$ ) polyps were $\geq 2$ to $<4 \mathrm{~cm}$. Thirty-six (31\%) polyps were $>4 \mathrm{~cm}$ ( $\triangleright$ Table 2 ). The vast majority of polyps without attempted endoscopic polypectomy were adenomas (97\%; 25 TAs, 88 TVAs, 1 TSA, 4 SSLs). Polyps $\geq 2 \mathrm{~cm}$ were significantly more likely to be TVAs compared to polyps $<2 \mathrm{~cm}$ (81 of $92 ; 88 \%, 95 \% \mathrm{Cl}$ [86-93] vs 7 of $26 ; 27 \%, 95 \% \mathrm{Cl}[13.7-46.1])(P<0.01)$. Of the 26 polyps that were $<2 \mathrm{~cm}, 15.4 \%$ were serrated polyps (4 SSLs; $95 \% \mathrm{Cl}[6.2 \%-33.5 \%])$ while only $1.1 \%$ (1 TSA; $95 \% \mathrm{Cl}[0.2-$ $5.9])$ of 92 polyps $\geq 2 \mathrm{~cm}$ were serrated $(P<0.05)$. No statistical significance was shown when comparing the presence of highgrade dysplasia between the 2 groups.

In this group, two polyps (1.7\%) were located at the appendiceal orifice (sizes $0.6 \mathrm{~cm}$ and $1.2 \mathrm{~cm}$ ) and $8(6.8 \%)$ were located at the ileocecal valve (range $1.7 \mathrm{~cm}-5.8 \mathrm{~cm}$ ). Two $(1.7 \%)$ polyps were either ulcerated or depressed and did not raise after saline lift (sizes were $\geq 2 \mathrm{~cm}$ in both).

\section{Potentially avoidable surgery for patients without attempted endoscopic polypectomy}

Twenty-six of 118 polyps (22\%; 23 in the right, 3 in the left coIon) $<2 \mathrm{~cm}$, macroscopically. In 92 of 118 polyps (78\%; 66 in right, 26 in the left colon) of 118 polyps, the macroscopic size was $\geq 2 \mathrm{~cm}$. Polyps that were $<2 \mathrm{~cm}$ were mostly located in the right colon $(89 \%, 95 \% \mathrm{Cl}[71-96]$ versus $72 \%, 95 \% \mathrm{Cl}[61.8-$ 79.9] for polyps $\geq 2 \mathrm{~cm}$ ) ( $\triangleright$ Table 2 ). However, no statistical sig- 
- Table2 Surgical referral patterns.

\begin{tabular}{|l|c|}
\hline N $=\mathbf{1 4 4}$ & \\
\hline No attempted endoscopic polypectomy, $\mathrm{n}(\%)$ & $118(82 \%)$ \\
\hline Polyp $<2 \mathrm{~cm}, \mathrm{n}(\%)$ & $26(18 \%)$ \\
\hline - Right colon & $23(16 \%)$ \\
\hline - Left colon & $3(2 \%)$ \\
\hline Polyp $\geq 2 \mathrm{~cm}, \mathrm{n}(\%)$ & $92(64 \%)$ \\
\hline - Right colon & $66(46 \%)$ \\
\hline - Left colon & $26(18 \%)$ \\
\hline Polyp $\geq 2 \mathrm{~cm}$-<4 cm & $56(39 \%)$ \\
\hline Polyp $\geq 4 \mathrm{~cm}$ & $36(25 \%)$ \\
\hline Size overestimation, $\mathrm{n}(\%)$ & $18(13 \%)$ \\
\hline Polyp $<2 \mathrm{~cm}$ with size overestimation, $\mathrm{n}(\%)$ & $7(5 \%)$ \\
\hline Polyp $\geq 2 \mathrm{~cm}$ with size overestimation, $\mathrm{n}(\%)$ & $11(8 \%)$ \\
\hline Incomplete endoscopic resection, $\mathrm{n}(\%)$ & $22(15 \%)$ \\
\hline Residual polyp <2 cm, n (\%) & $12(8 \%)$ \\
\hline - Right colon & $10(7 \%)$ \\
\hline - Left colon & $2(1 \%)$ \\
\hline Residual polyp $\geq 2 \mathrm{~cm}, \mathrm{n}(\%)$ & $10(7 \%)$ \\
\hline - Right colon & $6(4 \%)$ \\
\hline - Left colon & $4(3 \%)$ \\
\hline dromes, $\mathrm{n}(\%)$ & \\
\hline
\end{tabular}

nificance $(P>0.05)$ was demonstrated with regard to location (right versus left colon) between the two groups.

Eighteen of 118 polyps (15\%) polyps were found to have had size overestimation during endoscopy as previously defined. The majority of polyps with size overestimation were in the right colon (78\%; 14 polyps) ( $\downarrow$ Table 2 ). There were seven surgical resections that met both criteria of size $<2 \mathrm{~cm}$ and size overestimation.

\section{Surgery for incomplete endoscopic resection or recurrent polyps}

Of the 144 patients, 22 (15\%) underwent surgical resection for incomplete endoscopic polypectomy of adenomas (10 TAs; 12 TVAs). Among these, 12 (54.5\%) polyps had a residual polyp diameter of $<2 \mathrm{~cm}$ (10 in the right colon; $83.3 \%$, 95\% Cl [55.295.3] and two in the left colon; $16.7 \%, 95 \% \mathrm{Cl}$ [4.7-44.8]) and 10 polyps (45.5\%) had a residual diameter of $\geq 2 \mathrm{~cm}$ ( 6 in the right colon; $60 \%, 95 \% \mathrm{Cl}$ [31.3-83.2] and 4 in the left colon, $40 \%, 95 \% \mathrm{Cl}$ [16.8-68.7]). The mean of the residual polyp diameter was $1.9 \mathrm{~cm}$ ( $\triangleright$ Table 2 ). There was no statistical difference $(P>0.05)$ between the diameters of residual polyp in the right and left colon.
- Table 3 Surgical adverse events.

\begin{tabular}{|l|c|}
\hline & $\mathbf{N}=144$ \\
\hline Hospital stay (days), median (range) & $4.5(3.0-14.0)$ \\
\hline $\begin{array}{l}\text { Patients admitted to the intensive care } \\
\text { unit, } \mathrm{n}(\%, 95 \% \mathrm{Cl})\end{array}$ & $9(6.3 \% ; 3.3-11.5)$ \\
\hline $\begin{array}{l}\text { Intensive care unit stay (days), median } \\
\text { (range) }\end{array}$ & $3.0(1.0-10.5)$ \\
\hline $\begin{array}{l}\text { Patients with postoperative adverse } \\
\text { events, } \mathrm{n}(\%, 95 \% \mathrm{Cl})\end{array}$ & $29(20.1 \% ; 14.4-27.4)$ \\
\hline Postoperative adverse events type, $\mathrm{n}(\%, 95 \% \mathrm{Cl})$ \\
\hline - Postprocedural bleeding & $4(2.8 \% ; 1.1-6.9)$ \\
\hline - Wound infection & $4(2.8 \% 1.1-6.9)$ \\
\hline - Ileus & $11(7.6 \%)$ \\
\hline - Anastomotic leakage & $2(1.4 \%)$ \\
\hline - Urinary tract infection & $3(2.1 \% ; 0.7-6.0)$ \\
\hline - Pneumonia & $1(0.7 \% ; 0.1-3.8)$ \\
\hline - Sepsis & $3(2.1 \% ; 0.7-6.0)$ \\
\hline - Deep vein thrombosis & $1(0.7 \% ; 0.1-3.8)$ \\
\hline Mortality, $\mathrm{n}$ (\%, 95\% Cl) & $1(0.7 \% ; 0.1-3.8)$ \\
\hline
\end{tabular}

\section{Surgery for serrated polyposis syndrome or multiple polyposis syndrome}

Of the 144 cases, four (2.8\%) were referred to surgery for having $>10$ adenomas or met the definition of serrated polyposis syndrome [14].

\section{Percentage of cases with potentially avoidable surgical resections}

In total, 59 patients (41\%) could have potentially avoided surgical intervention ( $\triangleright$ Table 2 ). 22 polyps had incomplete resections, 26 polyps were $<2 \mathrm{~cm}$, seven of which also had size overestimation precluding endoscopic polypectomy. The remaining 11 polyps with size overestimation had sizes ranging from 2.0 to $3.5 \mathrm{~cm}$, only two of which had a size $>3 \mathrm{~cm}(3.2$ and $3.5 \mathrm{~cm})$. Moreover, of the 56 polyps/adenomas $\geq 2$ to $<4 \mathrm{~cm}, 23$ (16\%) had a polyp size $<3 \mathrm{~cm}$ (18 in the right, 5 in the left colon) and $33(23 \%)$ had a polyp size $<4 \mathrm{~cm}$ ( 23 in the right and 10 in the left colon) which is likely to increase the number of cases that could have benefited from expert referral with ability to remove larger polyps, prior to surgery. When including polyps $\geq 2$ to $<4 \mathrm{~cm}$, the percentage of patients that could have potentially avoided surgical resection reaches up to $80 \%$.

\section{Adverse events}

The median hospital stay was 4.5 days (range 3.0-14.0 days). Nine patients $(6.3 \%)$ were admitted to the intensive care unit (ICU) after surgery with a median duration of 3.0 days (range 1.0-10.5 days). A total of 29 patients $(20.1 \%$, $95 \% \mathrm{Cl}$ [14.427.4]) had postoperative adverse events (AEs), which are 
further specified in $>$ Table 3 . Mortality related to the SR was $0.7 \%(95 \% \mathrm{Cl}[0.4-3.8])$.

\section{Discussion}

Despite its efficacy and the strong evidence favoring endoscopic resection, partial colectomies for benign colorectal polyps are on the rise in the United States [15]. An analysis of a large data sample from Healthcare Cost and Utilization Project National Inpatient Sample (NIS) showed a concerning significant increase in the incidence of surgery for non-malignant colorectal polyps from 5.9 in 2000 to 9.4 in 2014 per 100,000 individuals [7]. This increase was observed in both men and women and across different races and age groups, especially among adults 50 to 79 years old. Certainly, these shifting trends in management do not come without costs, both financial and safety-related. Several studies have shown that major adverse postoperative events are relatively common in patients undergoing surgery for a non-malignant colorectal polyp. In one study, the risk of at least one major postoperative event was as high as $14 \%$ [4]. In addition, a nationwide analysis of $>$ 260,000 surgeries for non-malignant colorectal polyps from the National Inpatient Sample (NIS) over a 10-year period (2005-2014) showed an overall in-hospital mortality rate of $0.8 \%$ and a morbidity rate as high as $25 \%$ [8] both in line and comparable to the rates from our institution. Not surprisingly, this substantial risk of postoperative AEs was associated with a $106 \%$ increase in mean hospital length of stay and a $91 \%$ increase in mean hospitalization cost. Although multivariable logistic regression analysis established an association between postoperative morbidity risk with increasing age, male sex, black race, open surgical technique, and the presence of comorbidities, the study provided additional support for attempting endoscopic resection prior to surgical referral. In comparison, the complications most commonly associated with advanced endoscopic resection include intra-procedural bleeding (11\%) [16], delayed bleeding (6\%) [17] and perforation (1.5\%) for large polypectomies [3]. Mortality directly related to endoscopy or subsequent surgery after endoscopy is rare (0.08\%) [3].

Modern endoscopic colorectal polyp assessment and management offers advantages over surgical resection in terms of safety and decreased cost while maintaining efficacy in diagnosis and definitive management of most benign colorectal neoplasms [1-4]. There is substantial evidence that endoscopic removal of a colonic adenomatous polyp significantly reduces the risk of colorectal cancer development [5]. This is, however, contingent on optimizing the quality of colonoscopy which can be monitored using adenoma detection rate (ADR), a surrogate marker that measures combined personnel and technique-dependent factors. An endoscopist's ADR is associated with the subsequent interval cancer risk, with lower ADR predicting higher risk of interval cancer [18]. To date, quality measures have predominantly focused on ADR in colorectal cancer prevention, but polypectomy competency is rarely reported. A recent prospective study that included a series of 120 polypectomies performed by 12 endoscopists showed that polypectomy competency did not correlate with ADR or colonoscopy in- spection quality (CIQ) [19]. This highlighted the need to develop quality metrics that would independently evaluate polypectomy competency. Reliable tools to assess an endoscopist's technical skills and competence have been developed but have not been widely adopted [20,21]. Gupta et al. initially introduced Direct Observation of Polypectomy Skills (DOPyS) which uses a 4-tier grading system to score a set of parameters pertaining to the polypectomy procedure with a subsequent overall rating, based on video observations by expert assessors [20]. This method showed an agreement rate of up to $98 \%$ when assessing the success of the procedure and proved to be a reliable reflection of an endoscopist's competence when applied with a specific set of criteria, in more than one study [13, 20,22].

Polyp size, especially those $\geq 2 \mathrm{~cm}$, site and morphology are among the commonly reported variables that would add to the complexity of the endoscopic procedure and lead to surgical referral [7]. However, given the technical advancements in polypectomy techniques such as endoscopic submucosal dissection (ESD) and the published data on safety and cost effectiveness of endoscopic resection of advanced polyps [23], the guidelines set forth by the European Society of Gastrointestinal Endoscopy (ESGE) and the United States Preventive Services Task Force (USPSTF) on colorectal cancer recommend endoscopic resection as a preferred method to manage benign-appearing colorectal polyps $[3,4,24,25]$. When dealing with complex polyps, referral to an advanced endoscopist for repeat colonoscopy and attempted endoscopic resection, if appropriate, is recommended [6, 26-29]. These recommendations are based on evidence that $>90 \%$ of complex non-malignant colorectal polyps can be safely resected endoscopically regardless of size. In a meta-analysis, only $8.1 \%$ of patients with polyps $>2 \mathrm{~cm}$, predominantly laterally spreading sessile lesions, required surgery [3]. Nearly $60 \%$ of patients avoided surgical resection when repeat colonoscopy with polypectomy was performed, and similarly, $71 \%$ of lesions referred for surgery were actually amenable to endoscopic resection [30,31].

When examining the parameters responsible for the observed increase in surgical resection of non-malignant polyps, the role of endoscopists' skills and subjectivity in defining a complex polyp are an undeniable factor. This can be attributed, in part, to the lack of standardized quality measures for adequate endoscopic polypectomy. The Complete Adenoma Resection (CARE) study helped better characterize the rate of incompletely resected neoplastic polyps in clinical practice and evaluated potential contributing factors [12]. In this study, 346 endoscopically resected polyps were prospectively analyzed. The incomplete resection rate (IRR) was $10.1 \%$ and varied broadly among endoscopists. Moreover, the rate increased significantly with larger polyp size $(10-20 \mathrm{~mm})$ and sessile serrated histology. These findings could explain why incompletely resected polyps are estimated to account for $10 \%$ to $27 \%$ of interval colorectal cancers [11,32-34]. Other factors accounting for incomplete polyp removal may include right-sided location, lack of a contrast agent, intra-procedural bleeding, and endoscopist's skill level [10]. Another parameter that may contribute to surgical referrals in these cases is size overestimation during endoscopy. Estimation of a polyp size in vivo is a unique, but 
trainable skill set. For instance, one may use the width of an open forceps ( 7-8 mm depending on the model) or the diameter of an open snare to ascertain a more accurate estimate of the size of the lesion.

To assess the quality of endoscopic resection in clinical practice, our study focused on the characteristics of non-malignant polyps that are surgically resected as well as the indications for surgical referral. To our knowledge, this is the first study which included a large cohort from a tertiary care center that looked at the appropriateness of surgical removal of non-malignant polyps based on polyp size, location, morphology, histology and incomplete endoscopic resection rare. Unexpectedly, $22 \%$ of polyps that had no attempted endoscopic resection were $<2 \mathrm{~cm}$ which is not commensurate with the evidence-based guidelines and recommendations. The majority (85\%) of these smaller polyps were adenomas without depressed or ulcerated morphology in contrast with published data showing an association between surgical referral and sessile serrated lesions and/or complex configuration. Although not statistically significant, the majority $(89 \%)$ of these polyps were located in the right colon, which could be a starting point when trying to address the shortcomings and improve the quality of endoscopic polypectomy.

Our data also suggest that overestimation of polyp size might preclude endoscopic resection and contribute to surgical referral. Fifteen percent of polyps in our study had size overestimation. Moreover, $27 \%$ of polyps that were $<2 \mathrm{~cm}$ had been estimated to be $\geq 2 \mathrm{~cm}$ endoscopically. Upon reviewing the indications for surgery on these polyps, size was invariably the main indication listed. Interestingly, most (78\%) of the polyps with size overestimation were located in the right colon possibly due to technical difficulties in assessing proximal colon polyps. This also suggests that training for accurate polyp size measurement needs to be focused on proximal colon polyps.

When examining incompletely resected polyps which accounted for $15 \%$ of total cases, the majority (73\%) were located in the right colon as well. All of these polyps were either tubular or tubulovillous adenomas suggesting that adenomas, not just SSLs, can be associated with a higher rate of incomplete endoscopic resection. Moreover, over a half of the residual polyps measured $<2 \mathrm{~cm}$ in maximum diameter on follow-up. Nonetheless, surgical resection was preferred over endoscopic re-excision attempt in these situations. It is not entirely clear why these smaller sized residual polyps tended to be located in the right colon rather than left, but this could be due to higher incidence of incomplete resection rate in the right colon in general or physicians' reluctance to retreat polyp tissue in the right colon due to concerns about complications.

Our study shows that 59 patients $(41 \%)$ could have potentially avoided surgical intervention given the size of the polyps/residual polyps that were $<2 \mathrm{~cm}$. Furthermore, polyps with size $\geq 2$ to $<4 \mathrm{~cm}$ ( $48 \%$ of polyps without attempted endoscopic polypectomy) could potentially be removed by a more experienced endoscopist which could dramatically increase the percentage of avoidable surgeries. It is important to emphasize that our study design which included a polyp size cutoff of $2 \mathrm{~cm}$ was based on two expert opinions from gastroenter- ologists in the field that proposed a minimum polyp size that can be resected by the vast majority of practicing endoscopists given that there are no standard guidelines for endoscopic management of colorectal polyps, nor are there specific and updated guidelines for advanced endoscopy or surgical referral. However, given the advancements in endoscopic polypectomy techniques and the overwhelming evidence that the vast majority of benign colorectal polyps can and should be managed endoscopically, a higher number of surgeries would have likely been avoided with expert endoscopist referral of larger and more complex polyps. Moreover, polyps in special locations such as the appendiceal orifice and ileocecal valve can also potentially benefit from expert referral prior to surgery (i.e., one case with a $0.6 \mathrm{~cm}$ polyp at the appendiceal orifice underwent surgical resection). This would be a justified first step given the complication risks and costs associated with surgery [4, 19]. It is worth mentioning that the surgical samples that we collected were from a tertiary care referral center, and thus our observation brings out a speculation regarding polypectomy practices in a community setting.

Our study has some limitations. Our data collection and interpretation were done retrospectively potentially missing some pertinent information related to the outcomes we had defined. In about $40 \%$ of cases of incomplete polypectomy, original polyp size could not be found in the EMR, as these were outside referrals, precluding establishing a meaningful association between the size and location of incompletely resected polyps. Additionally, the time period when the retrospective data were collected likely includes cases of surgically resected polyps when endoscopic polypectomy techniques were not as readily available or as advanced as present date although snare polypectomy has been around for some time and is effective in removing most polyps with size $\leq 2 \mathrm{~cm}$ without the need for surgery.

\section{Conclusions}

A large number of patients in this study underwent potential avoidable surgery for colorectal polyps which were likely endoscopically resectable, placing them at undue risks. Providing practicing endoscopists with tools for accurate polyp size estimation, enhanced training in proper polypectomy technique, and increased awareness that experts can safely remove the vast majority of benign colorectal polyps with emphasis on seeking that expert referral as a first step prior to surgery would be helpful. For those currently learning colonoscopy, standardized training in and documentation of proficiency in polypectomy using Direct Observation of Polypectomy Skills (DOPyS) or a similar system would be important.

\section{Competing interest}

The authors declare that they have no conflict of interest. 


\section{References}

[1] Law R, Das A, Gregory D et al. Endoscopic resection is cost-effective compared with laparoscopic resection in the management of complex colon polyps: an economic analysis. Gastrointest Endosc 2016; 83: $1248-1257$

[2] Jayanna M, Burgess NG, Singh R et al. Cost analysis of endoscopic mucosal resection vs surgery for large laterally spreading colorectal lesions. Clin Gastroenterol Hepatol 2016; 14: 271-8 e1-2

[3] Hassan C, Repici A, Sharma P et al. Efficacy and safety of endoscopic resection of large colorectal polyps: a systematic review and meta-analysis. Gut 2016; 65: 806-820

[4] Peery AF, Shaheen NJ, Cools KS et al. Morbidity and mortality after surgery for nonmalignant colorectal polyps. Gastrointest Endosc 2018; 87: 243-250 e2

[5] Winawer S], Zauber AG, Ho MN et al. Prevention of colorectal cancer by colonoscopic polypectomy. The National Polyp Study Workgroup. N Engl J Med 1993; 329: 1977-1981

[6] Kaltenbach T, Anderson JC, Burke CA et al. Endoscopic removal of colorectal lesions-recommendations by the US Multi-Society Task Force on Colorectal Cancer. Gastrointest Endosc 2020; 91: 486-519

[7] Peery AF, Cools KS, Strassle PD et al. Increasing rates of surgery for patients with nonmalignant colorectal polyps in the United States. Gastroenterology 2018; 154: 1352-1360 e3

[8] Ma C, Teriaky A, Sheh S et al. Morbidity and mortality after surgery for nonmalignant colorectal polyps: a 10-year nationwide analysis. Am J Gastroenterol 2019; 114: 1802-1810

[9] Gallegos-Orozco JF, Gurudu SR. Complex colon polypectomy. Gastroenterol Hepatol (N Y) 2010; 6: 375-382

[10] Pedersen IB, Loberg M, Hoff G et al. Polypectomy techniques among gastroenterologists in Norway - a nationwide survey. Endosc Int Open 2018; 6: E812-E820

[11] Robertson DJ, Lieberman DA, Winawer SJ et al. Colorectal cancers soon after colonoscopy: a pooled multicohort analysis. Gut 2014; 63 : 949-956

[12] Pohl H, Srivastava A, Bensen SP et al. Incomplete polyp resection during colonoscopy-results of the complete adenoma resection (CARE) study. Gastroenterology 2013; 144: 74-80 e1

[13] Duloy AM, Kaltenbach TR, Wood M et al. Colon polypectomy report card improves polypectomy competency: results of a prospective quality improvement study (with video). Gastrointest Endosc 2019; 89: $1212-1221$

[14] Dekker E, Bleijenberg A, Balaguer F et al. Update on the World Health Organization Criteria for Diagnosis of Serrated Polyposis Syndrome. Gastroenterology 2020; 158: 1520-1523

[15] Zogg CK, Najjar P, Diaz AJ et al. Rethinking priorities: cost of complications after elective colectomy. Ann Surg 2016; 264: 312-322

[16] Ma MX, Bourke MJ. Complications of endoscopic polypectomy, endoscopic mucosal resection and endoscopic submucosal dissection in the colon. Best Pract Res Clin Gastroenterol 2016; 30: 749-767

[17] Burgess NG, Metz AJ, Williams SJ et al. Risk factors for intraprocedural and clinically significant delayed bleeding after wide-field endoscopic mucosal resection of large colonic lesions. Clin Gastroenterol Hepatol 2014; 12: 651-661 e1-3

[18] Kaminski MF, Wieszczy P, Rupinski M et al. Increased rate of adenoma detection associates with reduced risk of colorectal cancer and death. Gastroenterology 2017; 153: 98-105
[19] Duloy A, Keswani R, Yadlapati R et al. Polypectomy competency does not adequately correlate with colonoscopy inspection quality: the need for a polypectomy quality metric: 138 . A J Gastroenterol 2017; 112: $\mathrm{S} 66$

[20] Gupta S, Anderson J, Bhandari P et al. Development and validation of a novel method for assessing competency in polypectomy: direct observation of polypectomy skills. Gastrointest Endosc 2011; 73: 12321239 e2

[21] Patel SG, Duloy A, Kaltenbach T et al. Development and validation of a video-based cold snare polypectomy assessment tool (with videos). Gastrointest Endosc 2019; 89: 1222-1230 e2

[22] Siau K, Dunckley P, Valori R et al. Changes in scoring of Direct Observation of Procedural Skills (DOPS) forms and the impact on competence assessment. Endoscopy 2018; 50: 770-778

[23] Gamaleldin M, Benlice C, Delaney CP et al. Management of the colorectal polyp referred for resection: A case-matched comparison of advanced endoscopic surgery and laparoscopic colectomy. Surgery 2018; 163: 522-527

[24] Gorgun E, Benlice C, Church JM. Does cancer risk in colonic polyps unsuitable for polypectomy support the need for advanced endoscopic resections? J Am Coll Surg 2016; 223: 478-484

[25] Ruhl C, Sayer B, Byrd-Holt D et al. Costs of digestive diseases. The burden of digestive diseases in the United States. US Department of Health and Human Services, Public Health Service, National Institutes of Health, National Institute of Diabetes and Digestive and Kidney Diseases.9-6443 Washington, DC: US Government Printing Office; 2008: 137-147

[26] Ferlitsch M, Moss A, Hassan C et al. Colorectal polypectomy and endoscopic mucosal resection (EMR): European Society of Gastrointestinal Endoscopy (ESGE) Clinical Guideline. Endoscopy 2017; 49: 270-297

[27] Pimentel-Nunes P, Dinis-Ribeiro M, Ponchon T et al. Endoscopic submucosal dissection: European Society of Gastrointestinal Endoscopy (ESGE) Guideline. Endoscopy 2015; 47: 829-854

[28] Rex DK, Bond JH, Winawer S et al. Quality in the technical performance of colonoscopy and the continuous quality improvement process for colonoscopy: recommendations of the U.S. Multi-Society Task Force on Colorectal Cancer. Am J Gastroenterol 2002; 97: 12961308

[29] Rex DK, Schoenfeld PS, Cohen J et al. Quality indicators for colonoscopy. Gastrointest Endosc 2015; 81: 31-53

[30] Voloyiannis T, Snyder M], Bailey RR et al. Management of the difficult colon polyp referred for resection: resect or rescope? Dis Colon Rectum 2008; 51: 292-295

[31] Friedland S, Banerjee $S$, Kochar R et al. Outcomes of repeat colonoscopy in patients with polyps referred for surgery without biopsyproven cancer. Gastrointest Endosc 2014; 79: 101-107

[32] Leung K, Pinsky P, Laiyemo AO et al. Ongoing colorectal cancer risk despite surveillance colonoscopy: the Polyp Prevention Trial Continued Follow-up Study. Gastrointest Endosc 2010; 71: 111-117

[33] Farrar WD, Sawhney MS, Nelson DB et al. Colorectal cancers found after a complete colonoscopy. Clin Gastroenterol Hepatol 2006; 4: 1259-1264

[34] Robertson DJ, Lieberman DA, Winawer SJ et al. 795 Interval Cancer After Total Colonoscopy: Results from a Pooled Analysis of Eight Studies. Gastroenterology 2008; 134: A-111-A-112 